\title{
Using Learning Communities to Support Cantonese/Mandarin Family Child Care Providers in a Professional Development Intervention Program
}

\author{
Yafen Lo ${ }^{1}$, Shu-Chen Yen $^{2} \&$ Shinchieh Duh ${ }^{3}$ \\ ${ }^{1}$ Department of Child and Family Studies, California State University-Los Angeles, California, United States \\ ${ }^{2}$ Department of Child and Adolescent Studies, California State University-Fullerton, California, United States \\ ${ }^{3}$ Department of Psychology, San Jose State University, California, United States \\ Correspondence: Yafen Lo, Department of Child and Family Studies, California State University-Los Angeles, \\ CA, 90032, United States. Tel: 1-323-343-4590. E-mail: ylo2@calstatela.edu
}

Received: May 16, 2017

Accepted: June 1, 2017

Online Published: June 22, 2017

doi:10.5539/jel.v6n4p127

URL: http://doi.org/10.5539/jel.v6n4p127

\begin{abstract}
High-impact educational practices can promote student involvement and learning outcomes, but are rarely tested in the community college setting - where involvement is a typical challenge to student success. For Family Child Care (FCC) providers, who tend to be older and overworked, higher-education training can be especially difficult The present study examined the use of learning communities as a high-impact practice in Project Vista Higher Education Academy (PVHEA), a two-year professional development intervention program for Cantonese/Mandarin FCC providers at the East Los Angeles College in California. Quantitative and qualitative data during the inaugural term (January 2012-December 2013) indicated that PVHEA successfully helped FCC providers access and complete college coursework towards Child Development degrees and credentials. Course completion rate reached $100 \%$, and the providers gradually increased course load while maintaining above-average grades. Positive changes were also observed in self-efficacy, aspirations, and professional image. The associated program challenges were discussed.
\end{abstract}

Keywords: adult learners, family child care providers, high-impact practices, learning communities, professional development

\section{Introduction}

\subsection{Background}

Licensed Family Child Care (FCC) is a major early childhood service that provides care and education in home settings for children under the age of three. In a 2015 report, the California Child Care Resources and Referral Network (CCCRRN) concluded that regular child care remains inaccessible for working families. With its low cost and flexible hours, FCC offers an affordable child care solution for parents who have traditional or non-traditional work schedules; $20 \%$ of its clients are from low-income families (Burstein \& Layzer, 2007). However, FCC supply has declined by 11\% between 2014 and 2015 (CCCRRN, 2015), jeopardizing the wellbeing of many young children and their families.

The decline in FCC supply has been associated with the lack of quality assurance with respect to licensing, training, financial resources, and operational support (e.g., Raikes et al., 2013). The quality of FCC can be evaluated by structural (e.g., environment and materials) and process (e.g., adult-child interaction) indicators (Doherty, Forer, Lero, \& LaGrange, 2006; Philips \& Morse, 2011), both of which reliably predict children's developmental outcomes (Loeb, Fuller, Kagan, \& Carroll, 2004; NICHD Early Child Care Research Network, 2004). However, current regulations are too lax to assure high quality FCC. For 41 states in the United States, the degree requirement for FCC providers is high school diploma, or less (Child Care Aware of America [CCAA], 2015a). In California alone, an estimate of 30,699 homes provide FCC services, only $23 \%$ of which were licensed and none accredited (CCAA, 2016).

To ensure high quality child care, it is vital for FCC providers to complete advanced training. Developmentally appropriate stimulation helps organize early synaptic connections in the brain and has been linked to long-term 
cognitive growth (Bruer, 2002; Elliot, 2000; Hirsh-Pasek \& Burchinal, 2006; Hyson, Horm, \& Winton, 2012). Childcare professionals who held post-secondary degrees in Child Development or related specializations are especially likely to support children with developmentally valuable resources and experiences (Doherty et al., 2006; Whitebook, 2003). Without a formal degree, completing college coursework and training in Child Development has also been linked to child-centered beliefs, effective guidance, and developmentally appropriate practices (Doherty, 2015). Because FCC serves many ethnic minority families (Los Angeles County Child Care Planning Committee [LACCCPC], 2011), part of the qualification is being able to relate to the families' cultural and linguistic background.

The pressing issue is to create programs that can address FCC providers' unique demands: to be supported in daily work and in advanced training. Specifically, FCC providers need assistance in various aspects, such as professional development, life and leadership skills, technology training, textbook lending, alternative scheduling, cohorted classes, tutoring, and integration into the college campus (LACCCPC, 2011). In their pursuit of college coursework, FCC providers need courses scheduled for nighttime or weekends, academic advisement heeding their particular realities, faculty who recognize and support their desire and struggle in learning, and technical assistance that helps with learning technologies.

\subsection{Project Vistas Higher Education Academy (PVHEA)}

Community colleges are the major training ground for child development professionals. In response to the challenges in assuring high quality FCC, the East Los Angeles College launched the Project Vistas Higher Education Academy (PVHEA) in January 2012 with the following mission: offer easy access to higher education and degree advancement, develop highly qualified Early Childhood Education (ECE) workforce, and change the public- and self-perception of FCC providers to ECE professionals. PVHEA was a two-year professional development intervention program designed for the Cantonese/Mandarin- and Spanish-speaking FCC providers in San Gabriel Valley of California, where $25.7 \%$ of the residents were Asian American and $44.7 \%$ Latino American (US Census 2000). Being culturally responsive, PVHEA created separate divisions for the Cantonese/Mandarin- and the Spanish-speaking FCC providers. (Note 1) The present study focused on the Cantonese/Mandarin FCC providers.

PVHEA aimed to assist FCC providers in accessing and advancing college coursework to obtain work related credentials, and/or Associate's/Bachelor's degrees in Child Development. The providers received individualized mentoring and support to complete various courses on the theories, principles, and practices of early childhood education, covering a wide range of topics such as prenatal development; growth and development; brain development; health, safety, and nutrition; developmentally appropriate curriculum; and culturally relevant curriculum. PVHEA also redesigned General Education (GE) courses (e.g., English and Math) to contextualize course learning for childcare professionals, as contextualized teaching and learning could promote student outcomes (Center for Student Success, 2009). Additionally, various peripheral supports were available to address the unique challenges faced by FCC providers when pursuing advanced studies: such as case management services, advisement, educational counseling, life and leadership skills, textbook lending, cohorted classes, basic technology training, tutoring, and integration into the college campus.

In the broader sense, PVHEA provided a framework for a higher-education academy for FCC providers. The framework includes the following facets: implement high impact educational practices; develop contextualized course learning; conduct outreach, recruitment, and planning sessions with collaborators; track and assess participant outcomes; provide language support services; offer contracted classes as determined by the service plan; create a lending library; and host networking/social-cohort events. Learning about its successes and challenges can be valuable in informing other programs with similar objectives.

\subsection{Learning Communities as a High Impact Practice in PVHEA}

The Association of American Colleges and Universities (AAC\&U) named 10 high-impact practices, including first-year seminars and experiences, common intellectual experiences, learning communities, writing-intensive courses, collaborative assignments and projects, undergraduate research, diversity/global learning, service learning, community-based learning, internships, and capstone courses and projects. These practices are effective in increasing student engagement and retention in higher education (Kilgo, Sheets, \& Pascarella, 2015). According to Astin's Student Involvement Theory (1984), a student's physical and psychological engagement in school is closely linked to academic and developmental success. As student involvement increases (e.g., working on campus, living on campus, reviewing course materials, socializing with classmates or faculty), student learning as well as personal growth improves. For example, Whitebook et al. (2006) found that student cohorts provided resources for enhanced peer learning (higher involvement) as well as career development (better 
outcome). HIPs are deemed effective because they require dedication and time commitment from students, facilitate learning outside of the classroom, and encourage student collaborating and interacting with faculty members (Kuh, 2008) - all of which increases student involvement.

Limited involvement poses a major constraint for FCC providers to pursue college coursework and benefit from college experience. The providers typically work extensive hours to accommodate parents who have traditional and non-traditional work schedules. In addition to full-time child care, $10 \%$ of FCCs also provide before/after school care (CCAA, 2015b). Extensive hours working at home disadvantages FCC providers' college learning experience, due to reduced physical investment (less time to spend at school) as well as reduced psychological investment (less energy to tackle coursework).

In efforts to promote student involvement and development, PVHEA implemented one of the HIPs: learning communities. Briefly, learning communities incorporates the cohort structure in which students take several linked courses as a group, on topics that involve students and faculty with "'big questions' that matter beyond the classroom" (AAC\&U, 2007, p. 53). Learning communities have been associated with positive outcomes in four-year institutions, including high academic performance (Zhao \& Kuh, 2004), as well as increases in critical thinking and appreciation of diversity (Inkelas, Vogt, Longerheam, Owen, \& Johnson, 2006; Pike, Kuh, \& McCormick, 2010). PVHEA targeted learning communities because they may be especially impactful for FCC providers' college experience. Not only do FCC providers tend to value cohort programs that promoted long-term and trustful relationships with colleagues and instructors (Lanigan, 2010), their shared background in Child Development also facilitates connections beyond the classroom. In PVHEA, the providers took classes as a cohort and worked closely with their colleagues, professors, counselors, and supplemental coaches (who tutored in one-on-one or small group settings). PVHEA designed and offered a set of GE and major-specific courses contextualized in child development, so that to help learners appreciate how various courses would come to support their educational and career objectives.

Prior research has assessed HIPs primarily in four-year institutions and not two-year institutions such as community colleges (Center for Community College Student Engagement, 2014). Understanding how HIPs affect student success in community colleges is important for two reasons. First, community colleges education paves the foundation for students to pursue advanced degrees at four-year institutions. In the 2013-2014 academic year, about $46 \%$ of all students who completed their Bachelor's degrees had enrolled in community colleges during the 10 years prior to entering the four-year institutions (National Student Clearing House, 2015). Constant efforts have been made over the years to facilitate a smooth transition from two- to four-year institutions in the State of California (WICHE, 2016). Second, many professions require only Associate's degrees for career entry. Community college education thus directly affects students' preparation for the workforce. The present study focused on a group of Cantonese/Mandarin FCC providers who participated in PVHEA's inaugural term to examine the role of learning communities in providers' academic, professional, and personal growth in the program.

\section{Method}

\subsection{Participants}

Participants were 70 Cantonese/Mandarin speaking FCC providers (53 females, 17 males) who were enrolled in PVHEA between Spring 2012 and Fall 2013 sessions. The participants ranged in age from 21 to 74 years old ( $M$ $=49.43, S D=12.06)$ and had lived in the U.S. for 18.89 years on average $(S D=7.64)$. For the level of prior education, 70\% were below High School, 24\% received High School diploma or equivalent, and 6\% did not report. The average professional experience in FCC was 8.65 years; $71 \%$ were owners and $29 \%$ assistants. The number of children each provider served averaged $11.36(S D=3.12)$, and $73 \%$ were under 3 years old. Enrollment fluctuated slightly across sessions, but 50 of 70 participants joined in the first session, and enrollment averaged more than 50 participants per session. The recruitment advertisement was forwarded to agencies such as California Department of Social Services, Resource and Referral Program, Los Angeles Family Child Care Association, etc.

At the end of the two-year term, eight providers participated in a focus group interview. They represented those who completed at least two sessions in PVHEA and were thus knowledgeable enough to reflect on program services. The mean age for this group was 51.25 years old (range $=26$ to 63 years), majority of whom were above 50 years old and had immigrated from China or Hong Kong in adulthood. Six participants spoke primarily Cantonese (with working proficiency in Mandarin), one primarily Mandarin, and one 26-year-old provider born in the U.S. fluently English and Mandarin. The group ranged in FCC experience from 3 to 17 years. Most of them were reluctant to disclose their prior educational attainment, likely due to their embarrassment about 
limited schooling. (Note 2) A Mandarin-speaking female researcher led the focus group, assisted by the program coordinator and one supplemental coach to occasionally facilitate conversations.

\subsection{Measures}

Three major avenues were explored to examine the participants' experiences and provide feedback on program effectiveness. First, PVHEA quarterly reports and student records were collected to assess the program's educational and advancement efforts. The quarterly reports outlined services provided, course schedules, and periodic program outcomes. Student records included FCC providers' demographic information, educational attainment, courses taken, and GPAs. Second, a technology self-assessment survey was administered at the outset of the program in Spring 2012 (pretest) and again one year later in Spring 2013 (posttest) to evaluate the outcome of technology skills training. The survey consisted of six areas of computer literacy skills (a total of 48 yes-no questions): Basic computer operations and concepts, Word processing skills, Spreadsheet skills, Internet, Email, and Etudes/A.C.E. Portal (course registration system). The survey was translated into Chinese (the shared written language between Cantonese and Mandarin speakers) for the providers to complete. The final analysis included data from 47 providers who completed both the pre- and post-test surveys. Finally, a two-hour focus group exit interview was administered to understand the providers' journey through PVHEA and to assess program outcomes. The researchers consulted with the Program Director to develop interview prompts that were aligned with the program objectives. Questions included background information (e.g., demographics, motivation for joining), course-related feedback, perceptions of growth through the program, and program evaluation and suggestion.

\section{Results}

\subsection{Quantitative Analyses: Course Learning Outcomes and Technology Competency}

Table 1 provides the breakdown of course units completed by the providers during the Spring, Summer, and Fall sessions of 2012, as an early program assessment. PVHEA's initial evaluation found that $89 \%$ of the participants required substantial support for English learning. To this end, PVHEA offered a remedial course on academic preparation and basic language skills. The effectiveness of this course was evident: Whereas the majority of the providers in Spring (62\%) and Summer (81\%) completed fewer than 2 units, the majority of those in Fall (83\%) completed 6 or more units. In merely one year, the proportion of full-time course load (12+ units) increased from $4 \%$ to $24 \%$, and the providers completed a total of 210 Child Development units and 251 GE units, with a cumulative group GPA of $3.59(S D=0.56)$.

Quarterly reports over the two-year term revealed further information about training outcomes and educational attainment. At the end of the program term, 52 participants were eligible for Child Development permits and certificates: 42 were eligible for Child Development permits ( 28 for assistant teacher, 12 for associate teacher, and 2 for teacher) and 10 for Child Development certificates ( 8 for assistant teacher and 2 for associate teacher). Course completion rate reached $100 \%$ : Students completed all attempted courses.

Table 1. Breakdown of completed units across the first year

\begin{tabular}{|c|c|c|c|c|c|c|}
\hline \multirow[b]{2}{*}{ Unit load } & \multicolumn{2}{|c|}{ Spring 2012} & \multicolumn{2}{|c|}{ Summer 2012} & \multicolumn{2}{|c|}{ Fall 2012} \\
\hline & $\mathrm{N}$ & $\%$ & $\mathrm{~N}$ & $\%$ & $\mathrm{~N}$ & $\%$ \\
\hline Academic Preparation only & 24 & $48.00 \%$ & 29 & $56 \%$ & 9 & $16.67 \%$ \\
\hline 1-2 units & 7 & $14.00 \%$ & 13 & $25.00 \%$ & & \\
\hline 3-5 units & 1 & $2.00 \%$ & & & & \\
\hline 6-8 units & 7 & $14.00 \%$ & 10 & $19.23 \%$ & 8 & $14.81 \%$ \\
\hline 9-11 units & 9 & $18.00 \%$ & & & 24 & $44.44 \%$ \\
\hline 12-14 units & 1 & $2.00 \%$ & & & 8 & $14.81 \%$ \\
\hline 15 and more units & 1 & $2.00 \%$ & & & 5 & $9.26 \%$ \\
\hline Total & $\mathbf{5 0}$ & $100.00 \%$ & 52 & $100.00 \%$ & 54 & $100.00 \%$ \\
\hline
\end{tabular}

Technology self-assessment mean scores across six areas of computer literacy (Figure 1) were analyzed using one-sample $t$-tests to examine changes from pretest to posttest. The scores increased significantly across all areas, 
$p$ s $<.01$, suggesting that technology skills training as a peripheral support service promoted the providers' technology competency.

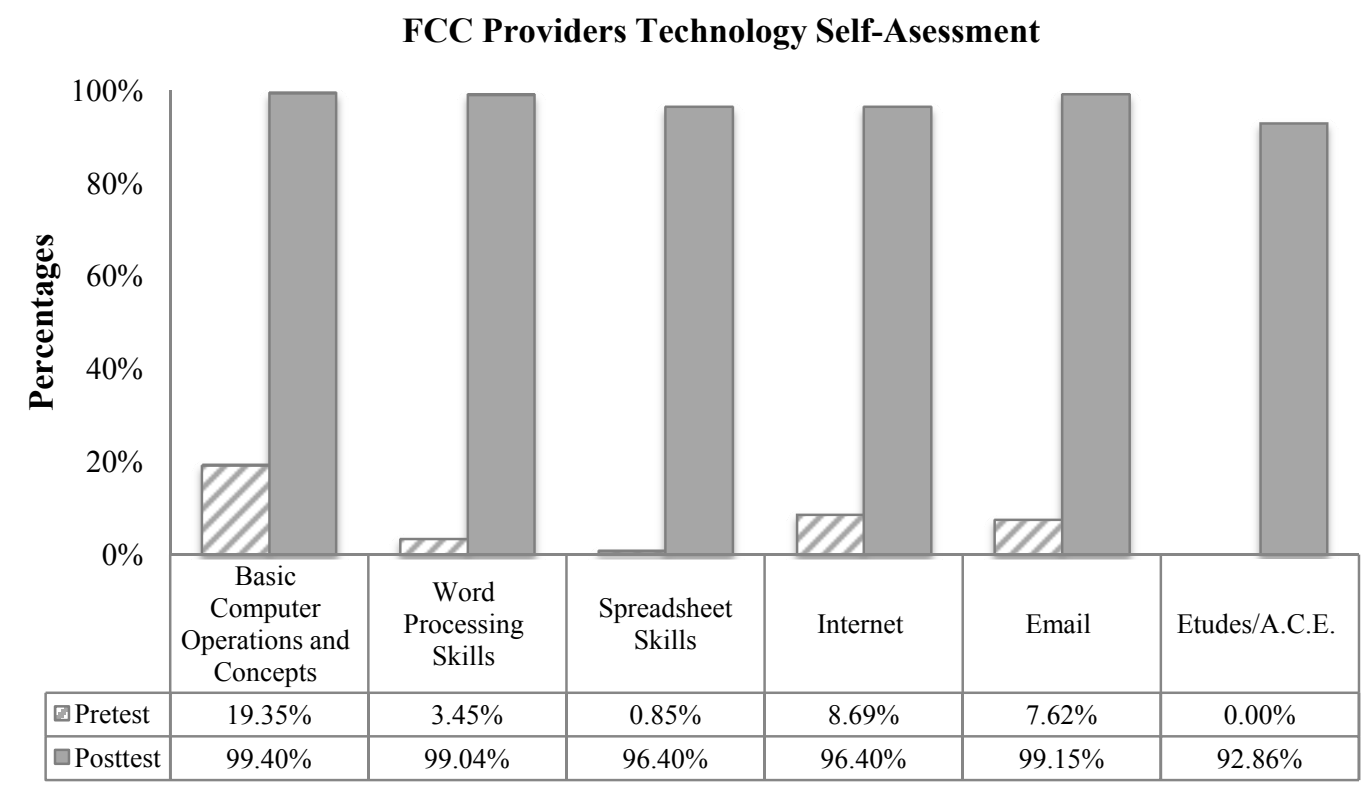

Figure 1. Providers' pretest and posttest technology self-assessment in the computer literacy skills

\subsection{Thematic Analyses: FCC Providers' Journey through PVHEA}

The focus group interview transcripts were translated into English and then verified by the researcher and the Mandarin-speaking division program coordinator, both of whom were proficient in English and Mandarin. Several major themes emerged and were described below.

\subsubsection{Endured Language Barrier in Course Learning}

For most of the providers, English was their second language and their top-most challenge for advanced coursework. Many FCC providers immigrated to U.S. in adulthood and tended to live in the ethnically homogeneous communities. For example, a couple in their early 60s stated that they had lived in a community exclusively for Cantonese/Mandarin speaking people and never had to speak English in their daily lives. Except for the U.S. born provider, everyone in the focus group named English as the biggest challenge in learning. Over the duration of the program, many had completed Speech 101, American Sign Language, and non-credit English, in addition to six other Child Development courses. They emphasized that the content was graspable, but they stumbled on the language barrier. Two providers mentioned that they could usually understand complex ideas in child development once they relate the ideas to their work, but the English barrier precluded this possibility.

All except the U.S. born provider felt intimidated by courses delivered in English and had to rely heavily on the supplemental coaches' support. As one provider commented on Speech 101, "I knew what kind of course it was and decided to postpone it for as long as I could. I would be scared to speak English in front of people. I took many Child Development courses, but not English or Speech courses until I had to." To support learning, the supplemental coaches previewed the course material with providers in both English and Mandarin, assisted in note-taking and clarification (of content) during class, reviewed course materials with providers, and translated lectures and textbooks when needed.

\subsubsection{Empowered by the Learning Community}

The providers greatly appreciated the learning community in the program. Some providers joined the program with their colleagues because they wanted peer support. Others thanked the program for introducing them to other colleagues who shared the same cultural, linguistic, and professional background. Although English was a major deterrent to college coursework, many providers became confident when they supported each other. They moved forward across courses by supporting each other psychologically and academically, such as working 
together, sharing information, and minding deadlines. One provider noted, "When I had a math problem at 2 a.m., it felt better to know that at the other end of the computer, my colleagues and supplemental coaches were still there. I felt upbeat when I knew that they were there for me." Another shared, "When I went to classes, I felt overwhelmed. They were all in English... If it weren't for friends' or supplemental coaches' help, I would not have survived."

Providers felt that the help from the supplemental coaches was vital beyond the classroom, especially their advices on time management. On average, the providers spent three to four hours per day on their schoolwork, but only after they finished work and care of their own family; many had been studying from midnight to around 4 a.m. One provider noted, "We used to finish our work around 6 p.m. when children were picked up by their parents. Then, we turned to manage our own family. With the extra school work, I had to find time to study and compete homework. Our supplemental coaches taught us tricks so that I worked on my assignment when children were asleep, or memorized notes for the tests when I was doing chores. I learned to manage time effectively so that I can take care of my career, family, and education."

The program staff also offered extended services to meet individual needs. One provider mentioned that the program coordinator taught her proper classroom behavior as well as coached her family members to encourage her study: "The program coordinator taught us how to behave in the American classroom and always encouraged us when we felt like giving up. She talked to my family to encourage and support me." The dedication to student success contributed to a strong sense of comradery in the learning community. As the aforementioned provider continued, "[The program coordinator] spent the weekend with us and sacrificed her own family time. I would feel ashamed if I did not do well in the class." Another provider added, "I told my husband (also a provider in the program) that 'you see the director still replied your email at 2 a.m. If you don't work to pass the class, you should feel very guilty', and he agreed."

\subsubsection{Increased Academic Aspirations}

Majority of the providers joined PVHEA without specific degree or credential objectives: They only wanted to advance their knowledge in early childhood education so that to increase child-centered care and refine their service. Gradually, the providers developed interests in pursuing professional certificates or advancing their education. One provider stated, "My friend and I thought that we would take one course and get done with it... We could not believe that we would make it. I used to feel ashamed talking about my degree. Now we feel excited about what else we can do. Can you imagine pursuing a college degree at our age?!" The exception was the 26-year-old, U.S. born FCC provider, who had been helping her mother's FCC since she was in high school. She felt that advanced degrees could bring her service to another level. She planned to complete her Associate's and Bachelor's degree.

\subsubsection{Developed Self-Efficacy and Better Image across Domains}

All providers indicated psychological changes when asked to reflect on their experience. For one, they felt more confident in academics. With the supplemental coaches' help, English was no longer a debilitating worry. After completing a few courses, they developed self-efficacy in managing time between school and work, and they understood how to get help and resources in the community college setting. Providers began to analyze what they were good at, identify the types of help they needed, and understand where to get help.

The providers also reported positive changes in their professional image, from caretakers to educators: They noticed their own transformation, and parents also showed more respect. As one member stated, "I used to think that I was just a nanny - even parents felt this way. I could not say much about when to teach what. Now I see myself as an educator who can really change children's lives. Parents trust me more when their children are under my care." Echoing this view, another provider noted, "I knew the better way to teach and communicate with children effectively. The other day I prepared some fine motor activities for the babies. They really enjoyed them. I realized I was doing what teachers were doing, and I was doing it the right way!"

Notably, the changes in the academic and professional domains engendered a positive influence on providers' own families. A couple of providers credited PVHEA for turning them into role models for their family: "When our kids saw us working so hard and studying so hard, they felt inspired. Even though we became busier, we had better interactions with our kids than before. They saw us working hard, they became more serious about their school work too." Indeed, the providers' college experience through PVHEA proved to their families that the American dream was attainable: As older immigrant adults, they could still access U.S. higher education. Providers felt that PVHEA had changed them forever, personally. 


\subsubsection{Acquired Practical Technology Skills}

All except the 26-year-old U.S. born provider agreed that their technology skills improved dramatically and they could utilize technology to better their work. One provider noted, "I used to do accounting by hand and never created a flier in my entire life. The professor taught us how to use Excel to do book keeping, and PowerPoint to create fliers for the new customers. That made me very proud of myself." Another provider said, "I did not have time to meet and was [too] shy to talk to professors. Now I could email them whenever I have the chance. I also emailed my supplemental coaches about course registration or homework and got instant responses. Internet really made my academic life easier."

\section{Discussion}

\subsection{Benefits of a Learning Community}

PVHEA's program effectiveness was demonstrated by the Cantonese/Mandarin-speaking FCC providers' achievement across multiple areas: college credits, knowledge of child development, classroom etiquettes, study skills, time management, technology competency, and most importantly self-perception and future educational goals. A key feature of PVHEA was the creation of a learning community, wherein students take a set of classes together and move forward as a cohort, working closely with each other and the program staff. When sharing their experience, the providers linked their learning community to several positive academic, professional, and personal outcomes: for example, mastery of coursework and the education system, application of course learning in professional practice, changing image from caretakers to educators, and increased confidence - to name a few. The benefit of learning communities is rarely reported with two-year college students or with those in professional development programs in the existing literature. Our findings suggested that learning communities could generate positive impacts on a professional development intervention program hosted at a community college, a program designed for FCC providers who had perceived college coursework as extremely daunting.

Although the present study did not measure changes in self-efficacy directly, the focus group interview revealed a wide range of positive psychological changes pointing to increased self-efficacy in both academic and professional domains. This result was consistent with Feldman and Kubota' (2015) findings on the strong correlations among hope, self-efficacy, optimism, and academic achievement in college students. PVHEA empowered the providers to pursue college coursework, and the providers gradually gained self-efficacy, along with positive academic (e.g., completed units and GPAs) and psychological (e.g., confidence) outcomes.

The learning community in PVHEA was extremely effective in producing positive outcomes via increased involvement. Over the program duration, the providers made more than 3,247 contacts with their supplemental coaches and advisors, more than $82 \%$ of the contacts were for tutoring and academic support. The focus group interview reports highlighted the strong relationships forged between the providers and the program staff. To overcome the language barrier, the providers worked closely with program staff who scaffolded the providers' learning by providing individualized support and cultivating the learning community. The providers reported feeling empowered by their peers and program staff to pursue more advanced professional permits or academic degrees - a sign that PVHEA successfully created a trusting and sustainable learning community in which the FCC providers can thrive.

The positive link between PVHEA's learning community and student success supported Hilliard's (2012) suggestion of utilizing professional learning communities. Program-implemented learning communities can be an effective approach in promoting student success because the curriculum is more student-centered, promotes active learning and collaboration among students, and is more contextualized for the intended workforce. FCC providers' focus group interview indicated that the different facets of PVHEA such as cohorted nature, curriculum design, coaching/tutoring, and peripheral supports were sensitive to the providers' needs and objectives, which made a successful learning community possible.

\subsection{The Challenges}

FCC providers differ from traditional college students in their work schedule, age, educational history, and language proficiency - all of which have posed special challenge to the administration and success of PVHEA. These challenges are not easily overcome and thus worth careful consideration in future program design and planning. 


\subsubsection{Scheduling Issues}

Typically, FCCs' operating hours range from 12 hours a day for five days a week, to 24 hours a day for seven days a week. Such intensive work schedules made it difficult for FCC providers to manage coursework. Balancing work, family, and school was a major concern for FCC providers because time was limited.

\subsubsection{Age-Related Cognitive Decline}

FCC providers were much older than traditional college students. For example, the mean age of the current sample was over 49 years old, with one-fourth of them over 60 years of age. Previous studies had found age-related declines in information-processing speed, inhibition, and working memory (Earles et al., 1997). Some providers mentioned that it took them a very long time and many attempts to learn the course materials and practice new skills. Age-related cognitive declines could mean additional work for both providers and the supporting program staff.

\subsubsection{Limited Prior Schooling}

The majority of FCC providers (70\%) did not complete high school. This created a noticeable gap between their academic preparation and instructors' expectations for college-level coursework. In addition, many of the providers were unfamiliar with U.S. classroom protocols. The program coordinator mentioned that some providers had to learn about basic classroom etiquette (e.g., raise hand before talking, respond to instructor's question, refrain from chatting during lecture) and about professionalism (e.g., being respectful of others, adhering to commitments, and maintaining ethical demeanors). The providers needed orientations and preparatory courses before they could tackle college coursework.

\subsubsection{Language Barriers}

Immense efforts were spent on translation and tutoring in the providers' native language to help them understand course contents. The supplemental coaches previewed the course materials before the class, assisted during the class, and held the review sessions after the class. It should be noted that supplemental coaches' responsibility went beyond instructional and linguistic supports for specific classes. They became language brokers for the providers in the areas of enrollment, financial aid, scholarships, degree or credential requirements for intended educational objectives, and computer literacy.

\section{Conclusions}

PVHEA was uniquely designed to advance educational access and attainment for Cantonese/Mandarin- or Spanish-speaking FCC providers. This study focused on the Cantonese/Mandarin providers and found that PVHEA successfully addressed the providers' needs and prepared them for early childhood workforce. The bilingual supplemental coaches' scaffolding facilitated an extraordinary learning community to support student success. The PVHEA created more access to higher-education opportunities for the Cantonese/Mandarin speaking FCC providers, with $100 \%$ course completion rate. Providers demonstrated remarkable growth in coursework, professional practice, and technological competency. These specific achievements were accompanied by positive psychological changes, as the providers reported higher confidence, further aspiration, and better self- and public-images. Overall, PVHEA was deemed a high-impact intervention program for Cantonese/Mandarin speaking FCC providers. Future research could include inquiries into how FCC providers apply course knowledge in their work by measuring their beliefs in developmentally appropriate practices, the quality of their interaction with children, and children's developmental outcomes in FCC settings.

\section{References}

Astin, A. W. (1984). Student involvement: A developmental theory for higher education. Journal of College Student Personnel, 25(4), 297-308.

Association of American Colleges and Universities. (2007). College learning for the new global century. Washington, DC: Association of American Colleges and Universities.

Bruer, J. T. (2002). Avoiding the pediatrician's error: How neuroscientists can help educators (and themselves). Nature Neuroscience, 5(Suppl), 1031-1033. https://doi.org/10.1038/nn934

Burstein, N., \& Layzer, J. (2007). National study of child care for low-income families: Patterns of child care use among low-income families, final report. Cambridge, MA: ABT Associates Inc.

California Child Care Resources and Referral Network. (2015). 2015 California child care portfolio. Retrieved from http://www.rrnetwork.org/2015_portfolio 
Center for Community College Student Engagement. (2014). A matter of degrees: Practices to pathways (High-impact practices for community college student success). Austin, TX: The University of Texas at Austin, Program in Higher Education Leadership.

Center for Student Success. (2009). Contextualized teaching and learning-A faculty primer: A review of the literature and faculty practices with implications for California community college practitioners. Retrieved from http://www.ccbsi.org/Webstites/basic skills/Images/CTL.pdf

Child Care Aware of America. (2015a). Child Care in America: 2015 State Fact Sheets (Introduction). Retrieved from http://usa.childcareaware.org/wp-content/uploads/2015/10/StateFactSheets_intro.pdf

Child Care Aware of America. (2015b). Child Care in the State of California. Retrieved from http://usa.childcareaware.org/wp-content/uploads/2015/10/2015-State-Fact-Sheets-California.pdf

Child Care Aware of America. (2016). State Child Care Facts in the State of: California. Retrieved from http://usa.childcareaware.org/wp-content/uploads/2016/07/California.pdf

Doherty, G. (2015). Quality in family child care: A focus group study with Canadian providers. Early Childhood Education Journal, 43(3), 157-167. https://doi.org/10.1007/s10643-014-0645-6

Doherty, G., Forer, B., Lero, D. S., \& LaGrange, A. (2006). Predictors of quality in family child care. Early Childhood Research Quarterly, 21(3), 296-312. https://doi.org/10.1016/j.ecresq.2006.07.006

Earles, J., Connor, L., Frieske, D., Park, D., Smith, A., \& Zwahr, M. (1997). Age differences in inhibition: Possible causes and consequences. Aging, Neuropsychology, and Cognition, 4(1), 45-57. https://doi.org/10.1080/13825589708256635

Elliot, L. (2000). What's going on in there? How the brain and mind develop in the first five years of life. New York, NY: Bantam Books.

Feldman, D. B., \& Kubota, M. (2015). Hope, self-efficacy, optimism, and academic achievement: Distinguishing constructs and levels of specificity in predicting college grade-point average. Learning and Individual Differences, 37, 210-216. https://doi.org/10.1016/j.lindif.2014.11.022

Hilliard, A. T. (2012). Practices and value of a professional learning community in higher education. Contemporary Issues in Education Research, 5(2), 71-74. https://doi.org/10.19030/cier.v5i2.6922

Hirsh-Pasek, K., \& Burchinal, M. (2006). Mother and caregiver sensitivity over time: Predicting language and academic outcomes with variable- and person-centered approaches. Merrill-Palmer Quarterly, 52(3), 449-485. https://doi.org/10.1353/mpq.2006.0027

Hyson, M., Horm D. M., \& Winton, P. J. (2012). Higher education for early childhood Educators and outcomes for young children: Pathways for greater effectiveness. In R. C. Pianta, W. S. Barnett, L. M. Justice, \& S. M. Sheridan (Eds.), Handbook of early childhood education. New York: Guildford.

Inkelas, K. K., Vogt, K. E., Longerheam, S. D., Owen, I., \& Johnson, D. (2006). Measuring outcomes of living-learning programs: Examining college environments and student learning and development. The Journal of General Education, 55(1), 40-76. https://doi.org/10.1353/jge.2006.0017

Kilgo, C. A., Sheets, J. K. E., \& Pascarella, E. T. (2015). The link between high-impact practices and student learning: Some longitudinal evidences. Higher Education, 69(4), 509-525. https://doi.org/10.1007/s10734-014-9788-z

Kuh, G. D. (2008). High-impact educational practices: What they are, who has access to them, and whey they matter. Washington, DC: Association of American Colleges and Universities.

Lanigan, J. D. (2011). Family child care providers' perspectives regarding effective professional development and their role in the child care system: A qualitative study. Early Childhood Education Journal, 38(6), 399-409. https://doi.org/10.1007/s10643-010-0420-2

Los Angeles County Child Care Planning Committee. (2011). The Los Angeles County Child Care and Development: Needs Assessment. Retrieved from http://www.ceo.lacounty.gov/ccp/pdf/2011\%20\%20Needs\%20Assessment_Website\%20Version_21March1 2.pdf

Loeb, S., Fuller, B., Kagan, S. L., \& Carroll, B. (2004). Childcare in poor communities: Early learning effects of type, quality, and stability. Child Development, 75, 47-65. https://doi.org/10.1111/j.1467-8624.2004.00653.x 
NICHD Early Child Care Research Network. (2004). Type of child care and children's development at 54 months. Early Childhood Research Quarterly, 19, 203-230. https://doi.org/10.1016/j.ecresq.2004.04.002

National Student Clearinghouse. (2015). Snapshot report: Contribution of two-year institution to four-year completions. $\quad$ Retrieved from http://nscresearchcenter.org/snapshotreport-twoyearcontributionfouryearcompletions 17/

Phillips, B., \& Morse, E. (2011). Family child care learning environments: Caregiver knowledge and practices related to early literacy and mathematics. Early Childhood Education Journal, 39(3), 213-222. https://doi.org/10.1007/s10643-011-0456-y

Pike, G. R., Kuh, G. D., \& McCormick, A. C. (2010). An investigation of the contingent relationships between learning community participation and student engagement. Research in Higher Education, 52(3), 300-322. https://doi.org/10.1007/s11162-010-9192-1

Raikes, H., Torquati, J., Jung, E., Peterson, C., Atwater, J., Scott, J., \& Messner, L. (2013). Family child care in four Midwestern states: Multiple measures of quality and relations to outcomes by licensed status and subsidy program participation. Early Childhood Research Quarterly, 28(4), 879-892. https://doi.org/10.1016/j.ecresq.2013.06.001

US Census. (2000). Retrieved from https://www.census.gov/census2000/states/us.html

Whitebook, M. (2003). Early education quality: Higher teacher qualifications for better learning environments $-A$ review of the literature. Retrieved from http://www.irle.berkeley.edu/cscce/wpcontent/uploads/2003/01/Early_Ed_Quality.pdf

Whitebook, M., Sakai, L., Kipnis, F., Lee, Y., Bellm, D., Speiglman, R., ... Tran, P. (2006). California early care and education workforce study: Licensed family child care providers statewide 2006. Berkeley, CA: Center for the Study of Child Care Employment, and San Francisco, CA: California Child Care Resource and Referral Network.

WICHE. (2016). State Higher Education Policy Database. Retrieved from http://higheredpolicies.wiche.edu/content/policy/index

Zhao, C., \& Kuh, G. D. (2004). Adding value: Learning communities and student engagement. Research in Higher Education, 45(2), 115-138. https://doi.org/10.1023/B:RIHE.0000015692.88534.de

\section{Notes}

Note 1. Interviews with supplemental coaches confirmed that the English language presents bigger challenge in learning for the Cantonese/Mandarin than for the Spanish providers.

Note 2. One provider commented, "I used to feel ashamed talking about my degree" (see Increased academic aspirations under Thematic analyses).

\section{Copyrights}

Copyright for this article is retained by the author(s), with first publication rights granted to the journal.

This is an open-access article distributed under the terms and conditions of the Creative Commons Attribution license (http://creativecommons.org/licenses/by/4.0/). 